- Oil contamination will occur when oil-lubricated air turbine handpieces are used.

- Decontamination of cut surfaces is essential to ensure proper bonding, especially for self-etching systems.

- Oil-free handpieces may be a preferable alternative from this point of view.

\title{
Discharge of lubricant from air turbine handpieces
}

\author{
A. S. M. Pong, ${ }^{1}$ J. E. Dyson ${ }^{2}$ and B. W. Darvell ${ }^{3}$
}

\begin{abstract}
Objective To demonstrate and quantify the discharge of lubricating oil from high-speed air turbine handpieces whilst running.

Materials and methods Dye-marked oil (Kavospray, KaVo) was used to lubricate four handpieces (Quiet-Air, Midwest) and the air discharged from around the lower bearing was directed at the moving chart paper on a recorder whilst running for 40 minutes. Secondly, seven new handpieces (Quiet-Air, 300SE, Midwest; Topair 796, Topair 795, WEH; VIP- $\Sigma$, Pana-air, NSK; Lares, Lares Research) were cleaned, weighed and then lubricated with unmarked oil (Kavospray, KaVo). Oil discharge was determined gravimetrically over runs of 240 minutes. Data were fitted to the logistic dose response function.

Result The dye-marked oil tests showed that oil was discharged for at least 40 minutes in the direction of the bur. The gravimetric tests showed that oil continued to be discharged up to at least 240 minutes, and that the usual practice of removing excess lubricant by running for 1-2 minutes was ineffective in preventing cut-surface contamination. Significance Bonding procedures in dentistry may be jeopardised by oil contamination from hand piece lubricants. Decontamination with a detergent is suggested as a means of ensuring effective adhesive dentistry.
\end{abstract}

\section{INTRODUCTION}

Most air turbine handpieces in use today are of the ball-bearing type and require periodic lubrication for reasons of wear reduction, reduced friction and corrosion protection. Most manufacturers recommend routine lubrication before autoclaving, and this is normally performed by injecting into the air line at the connector a short spray of oil from a pressurized can. It is generally accepted that there is a need to expel excess lubricant by running the turbine for a short period before use yet there has apparently been no study of the effectiveness of this.

It appears to be well-understood that saliva contamination of acid-etched enamel significantly reduces the bond strength which can be achieved between that surface and a restorative material. However, contamination is not limited to that of saliva. As might have been anticipated, it has been shown that handpiece lubricants

\footnotetext{
${ }^{1 *}$ Part-time Clinical Lecturer, Oral Rehabilitation; ${ }^{2}$ Clinical Lecturer, Oral Rehabilitation; ${ }^{3}$ Reader, Dental Materials Science, Faculty of Dentistry, The University of Hong Kong, Hong Kong.

${ }^{*}$ Correspondence to: Dr John Dyson, 4/F, Prince Philip Dental Hospital, 34 Hospital Road, Hong Kong

Email:jdyson@hku.hk
}

\section{Refereed paper}

Received 10.12.03; Accepted 19.04.04

doi: 10.1038/sj.bdj.4812353

(๑) British Dental Journal 2005; 198: 637-640 are included in the list of contaminants which can seriously impair such bonding. The obvious source of such contamination is the handpiece itself during cavity preparation. Again, this risk is not known to have been given attention in common operative technique textbooks.

Due to the dearth of information, yet clear importance of the issue, the discharge of lubricant from air-turbine handpieces was investigated with a view to characterising the risk, and ascertaining whether procedures could be identified which would eliminate or minimise that risk.

\section{MATERIALS AND METHODS}

A preliminary visual check of the existence of the problem was made using dye-marked lubricant. Four examples of one brand of handpiece (Quiet-Air, see Table 1) were taken from the stock in daily use in the Prince Philip Dental Hospital, Hong Kong. A commonly-used handpiece lubricant (KaVo Spray, KaVo, Biberach-Riss, Germany) was chosen which, according to the manufacturer, is an iso-paraffin oil with a propane-butane mixture propellant. A quantity of this material was discharged from the spray can into a glass beaker and the propellant allowed to evaporate by standing for $24 \mathrm{~h}$. The oil was then marked by dissolving 0.2 g $100 \mathrm{~mL}^{-1}$ Oil Red 0 [BDH, Poole, England], close to saturation. UV-fluorescing dyes were considered but none were found to be as effective as the normal light-viewed dye. The marked oil was then used to lubricate the handpieces in the usual way by injecting into the drive air supply tube a 2 s spray driven from a pressure vessel by air at 1.7 -1.8 bar (ie the original spray can pressure) using a digital pressure indicator (Model DPI 260, Druck, Leicester, England) and pressure regulator (AW200002, SMC, Tokyo, Japan). Surplus oil was allowed to drain from the head of the handpiece for $30 \mathrm{~s}$ and the outer surface of the handpiece was wiped clean to remove excess oil before fitting a plain mandrel.

Each lubricated handpiece in turn was clamped with the mandrel vertical and its tip $1 \mathrm{~mm}$ from the centre line of the paper of a $150 \mathrm{~mm}$ wide strip-chart recorder (125-1A, Curken Scientific, Danbury, CT, USA) running at $20 \mathrm{~mm} \mathrm{~min}{ }^{-1}$. The handpiece was then run at the recommended operating pressure of 1.86 bar, with the pressure controlled and monitored as before, for $40 \mathrm{~min}$. The pattern of the discharged oil on the paper was then inspected. This was done in duplicate for the four Quiet-Air handpieces.

Given the outcome of the above demonstration, a quantitative (gravimetric) determination of the oil discharge was made. One new (unused) example of each of the seven current models of handpiece 


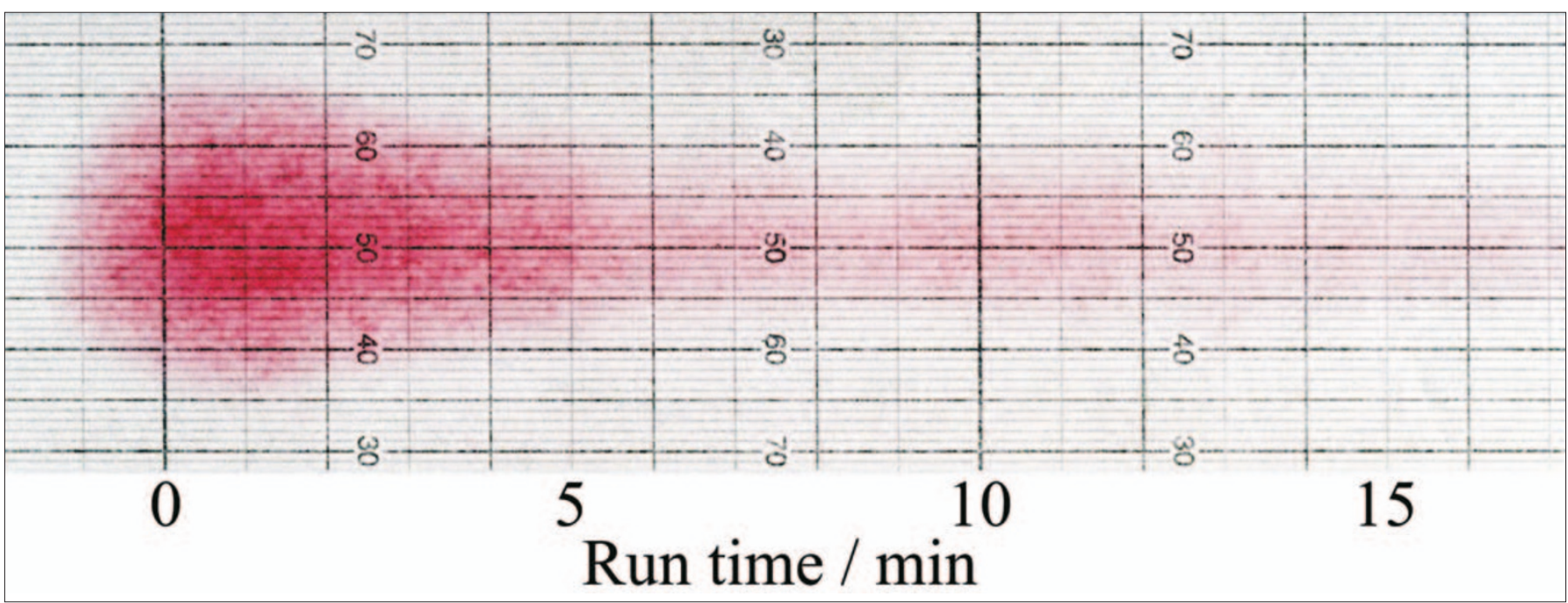

Fig. 1 Typical marked-oil discharge trace for a Midwest Quiet-Air handpiece.
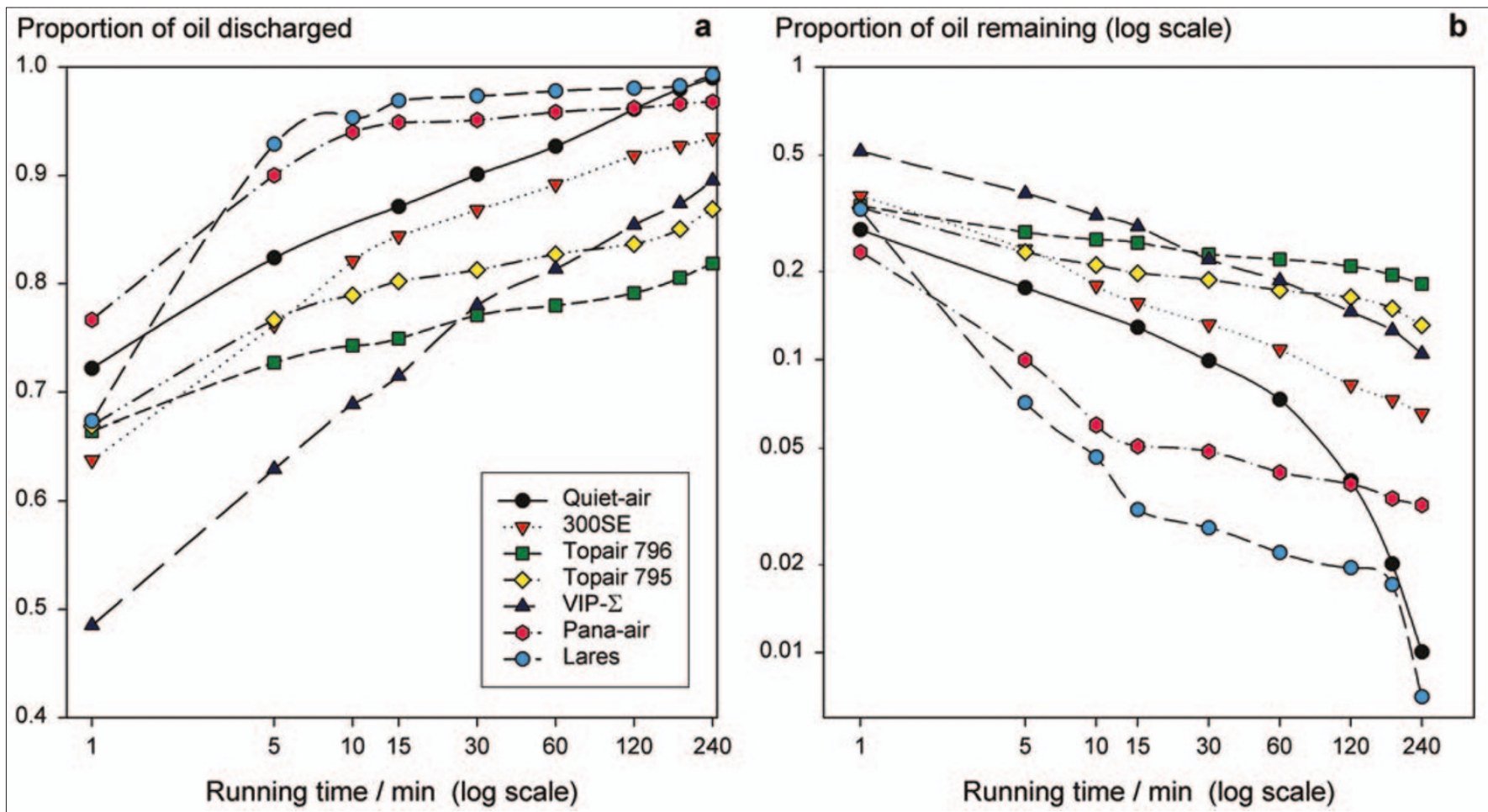

Fig. 2 Discharge of oil from air turbine handpieces while running. a: Proportion of original amount present discharged. b: Proportion of original amount of oil remaining.

was tested (Table 1). Prior to the test, each handpiece was first disassembled. The rotor head was removed from the shaft of the handpiece and all internal and external surfaces of the handpiece were cleaned and flushed thoroughly with 70\% ethyl alcohol before being allowed to dry. The handpiece was then reassembled and tare-weighed using an analytical balance (H5422, Mettler Instrumente AG, Greifensee, Switzerland) to $0.1 \mathrm{mg}$.

The same lubricant as in the visual demonstration was again used (KaVo Spray), but unmarked. It was degassed for about $10 \mathrm{~s}$ using a vacuum pump (ET8VS, Edward High Vacuum, Crawley, England) to reduce the content of volatiles before application. Lubrication was as before, surplus oil being allowed to drain for $10 \mathrm{~s}$. Oil on the outer surface of the handpiece was carefully wiped away with paper towels dampened with 70\% ethyl alcohol. Handling was with fine clean cotton gloves and absorbent paper to reduce contamination. The lubricated handpiece was then reweighed.

Each handpiece was then supplied with compressed air at the manufacturer's recommended operating pressure (Table 1), con- trolled and monitored as before. After running for 1, 5, 10, 15, 30, 60, 120, 180 and 240 minutes, the handpiece was stopped, the external surface cleaned as before with paper and 70\% ethanol, and reweighed. The amount of oil discharged was calculated by difference.

Curve-fitting of oil discharged against time was done in software (TableCurve 2D v. 5.1, SPSS, Chicago IL, USA) as was graphing (SigmaPlot v. 9, SPSS).

\section{RESULTS AND ANALYSIS}

A typical discharge recording is shown in Figure 1. It was evident that a considerable amount of oil was discharged within the first few minutes, but it also continued to be so in readily detectable amounts even at 40 minutes. The pattern of discharge was consistent for each of the four handpieces and on repetition.

The results of the gravimetric trials are shown in Figure 2. As can be seen from Table 1, the initial amount of oil retained varied widely so the plots of Figure 2 have been normalised, that is, the actual amount discharged expressed as a proportion of the initial 


\begin{tabular}{|c|c|c|c|c|c|c|c|c|c|c|}
\hline \multirow[t]{2}{*}{ Model } & \multirow[t]{2}{*}{ Manufacturer } & \multirow[t]{2}{*}{ Ser. No. } & \multirow{2}{*}{$\begin{array}{l}\text { Conn. } \\
\text { holes }\end{array}$} & \multirow{2}{*}{$\begin{array}{l}\text { Rec. } \\
\text { pressure } \\
\text { / bar }\end{array}$} & \multirow{2}{*}{$\begin{array}{l}\text { Initial } \\
\text { oil } \\
/ \mathrm{g}\end{array}$} & \multicolumn{4}{|c|}{ Logistic dose response curve parameter estimates } & \multirow[b]{2}{*}{ r2 } \\
\hline & & & & & & a & $b$ & c & width & \\
\hline \multirow[t]{2}{*}{ Quiet-Air } & Midwest, Des Plaines IL, USA & 302334 & 3 & 1.86 & 0.4668 & 0.560 & 0.124 & -0.203 & 27.20 & 0.9998 \\
\hline & & & & & & \pm 0.027 & \pm 0.037 & \pm 0.027 & & \\
\hline \multirow[t]{2}{*}{ 300SE } & Midwest, Des Plaines IL, USA & 921719 & 2 & 2.18 & 0.9392 & 0.925 & 0.238 & -0.420 & 3.24 & 0.9997 \\
\hline & & & & & & \pm 0.009 & \pm 0.019 & \pm 0.024 & & \\
\hline \multirow[t]{2}{*}{ Topair 796} & WEtH, Burmoos, Austria & 06260 & 4 & $2.2 \pm 0.1$ & 0.1213 & 0.109 & 0.007 & -0.216 & 1.14 & 0.9996 \\
\hline & & & & & & \pm 0.004 & \pm 0.003 & \pm 0.047 & & \\
\hline \multirow[t]{2}{*}{ Topair 795} & WEtH, Burmoos, Austria & 154722 & 4 & $2.2 \pm 0.1$ & 0.1372 & 0.121 & 0.056 & -0.412 & 0.86 & 0.9993 \\
\hline & & & & & & \pm 0.002 & \pm 0.020 & \pm 0.061 & & \\
\hline \multirow[t]{2}{*}{ VIP-G } & NSK, Tokyo, Japan & A41147 & 4 & $1.9-2.1$ & 0.3981 & 0.415 & 1.499 & -0.348 & 35.29 & 0.9998 \\
\hline & & & & & & \pm 0.002 & \pm 0.146 & \pm 0.016 & & \\
\hline \multirow[t]{2}{*}{ Pana-air } & NSK, Tokyo, Japan & AF33752 & 4 & $2.2 \pm 0.1$ & 2.8543 & 2.766 & 0.207 & -0.843 & 0.71 & 0.9998 \\
\hline & & & & & & \pm 0.008 & \pm 0.021 & \pm 0.051 & & \\
\hline Lares & $\begin{array}{l}\text { Lares Research, Chicago CA, } \\
\text { USA }\end{array}$ & EB898283 & 4 & 2.18 & 1.6547 & $\begin{array}{r}1.628 \\
\pm 0.004\end{array}$ & $\begin{array}{r}0.532 \\
\pm 0.018\end{array}$ & $\begin{array}{r}-1.230 \\
\pm 0.055\end{array}$ & 1.08 & 0.9998 \\
\hline
\end{tabular}

amount. Inspection showed that a satisfactory fit for each curve was obtained for the logistic dose response function:

$$
z=\frac{a}{1+\left(\frac{t}{b}\right)}
$$

where $t$ is the time, $z$ the cumulative amount of oil discharged, $a$ is the scale factor, $b$ the transition centre (ie the 50\% point), and $c$ controls the steepness of the plot. The values of the fitted parameters are shown in Table 1 along with the coefficient of determination for the fit $\left(\mathrm{r}^{2}\right)$ and the width of the transition $w$ calculated as:

$$
w=b\left(3^{-1 / c}-3^{1 / c}\right)
$$

In effect, the parameter $a$ estimates the amount of oil originally present. It can be seen from Table 1 that these two values do indeed match closely (regression $r^{2}=0.9982$ ).

In addition, as it is the small amounts of oil remaining that may be discharged that are of particular interest, the results are also plotted to emphasize the proportion $p$ remaining (Fig. 2b).

\section{DISCUSSION}

The graphic demonstration of long-continued oil discharge from a running handpiece was, with hindsight, not unexpected. The lubricant is expected to form a film on all (internal) surfaces as well as be held by capillarity in corners and crevices. Although much of this would be anticipated to blown out quite quickly, the remaining film would migrate under the influence of boundary layer drag only slowly because of the viscosity of the oil. Even so, it is to be noted that this discharge was recorded for the air escaping around the chuck in the direction of the bur, given that the main turbine exhaust is ducted back through the handpiece. The oil that escapes in that direction will therefore be dominated by that trapped in and around the lower bearing.

The gravimetric tests show that appreciable amounts of oil may be retained within a handpiece for a long period, despite being run, but importantly in the present context that oil will also continue to be discharged slowly. In contrast to the graphic test, the majority of the oil lost is expected to be lost through the normal exhaust duct and that only a somewhat smaller portion will be directed at the bur. To quantify these contributions separately would require a more elaborate arrangement. Even so, it seems to be unambiguous that, if oil is being lost, part of it is certain to emerge at the lower bearing since air escapes in this direction for all handpieces tested. Contamination of the workpiece will therefore be inevitable for all handpieces tested and at all times.

Lubricants have as their primary function the reduction of friction between moving parts both for efficiency and wear reduction; with high speed devices such as air turbines this is particularly important. However, these devices were introduced when bonding was not a procedure available to dentistry; this approach has been commonplace since the 1980s and is likely to increase in importance. It is therefore unfortunate that handpiece lubricating oil is to be expected as a contaminant of the surfaces prepared for bonding simply because it is present in the discharge airstream around the lower bearing. Indeed, it has been shown that such contamination compromises bonding. Although there is normally an instruction to run the handpiece for a short while after lubrication (typically 1-2 min), it is clear from the present work that while this may remove as much as 95\% even in, say, five minutes (Fig. 2a,b), appreciable oil remains to be discharged slowly and essentially indefinitely. This timing should be compared with the figures for the average daily use of air turbine handpieces, some 12 to $14.5 \mathrm{~min}$ but of course the time that a particular handpiece is used for one patient before autoclaving would be much shorter. The crucial point is that the user has no effective control over the discharge.

The logistic dose response function appears to provide a reasonable description of oil discharge behaviour across handpieces, but no strong claim is being made for its general validity other than as a guide. Given that, it is not easy to visualise the effects of the parameters other than $a$, which corresponds to the initial oil retained, for which values there is considerable variation. Clearly, the internal detail will affect how oil is trapped and how it is blown out. Allowing for that, there are still big differences in the characteristics of the various handpieces in terms of the values of the parameters $b$ and $c$, which essentially measure the rate at which the oil is discharged. That is, the curves are not merely dependent on the amount of oil initially present, even though variation between lubrication events would be expected.

There are some handpieces with ceramic bearings which are claimed to require no lubrication, although there appears to be no data available on long-term clinical performance to allow a judgement as to suitability to be made. Alternatively, use of a grease may prevent or limit the discharge of lubricant because the plastic nature of such materials (many are soaps) means that flow does not occur so easily. Whether they permit efficient high-speed running needs evaluation. There seems to be no practicable approach to preventing air (and therefore oil) being discharged at the lower bearing or around the chuck since any seal would limit the free-running speed of the turbine. 
As it stands then, and presumably for a great many handpieces in service, there appears to be no means for the user to avoid oilcontamination when a lubricant of this type is used. The only option is to decontaminate thoroughly the surfaces to be bonded. This might be achieved through the use of a detergent (such as is used in toothpastes, for known safety), with agitation such as might be provided with an ultrasonic probe immersed in the liquid, and thorough rinsing. Distilled or deionised water might be advisable for that as mains water, despite potability, may contain substances readily absorbable to clean surfaces. No products are currently known to be sold for this decontamination purpose and some work in this area would be required. Powers et al. reported that re-etching of tooth surfaces which have been contaminated by lubricant appears to allow normal bonding strength to be achieved, which suggests that merely etching the freshly-cut but contaminated surface would be sufficient. A specific test of this is required. If it is true, it might explain why the matter has not received any attention. However, aqueous etchants as used in dentistry cannot dissolve or emulsify such oils, and relying on 'undermining' release from the surface would seem to be unreliable without specific confirmation. The problem would appear to be more acute for selfetching bonding systems in which there is no rinsing step.

The work presented here is of a preliminary nature only, but it clearly demonstrates that there is the likelihood of cut-surface contamination with handpiece lubricant, primarily arising from air discharged around the lower bearing of the air turbine. Further work would be desirable to quantify the effects of type of lubricant, handpiece design and lubrication regime, but it is argued that the mere existence of the contamination is the problem, and that minimisation misses the point: it should be eliminated for critical work in bonding, so-called 'adhesive dentistry'.

\section{CONCLUSION}

That appreciable amounts of oil may be discharged from air turbine handpieces over long periods after lubrication seems to have gone unrecognised. This oil may contaminate critical surfaces, jeopardising bonding. If a lubricant-free or non-contaminating handpiece cannot be used, decontamination should be a routine procedure.

The work on which this paper is based was done in part-fulfillment of the requirements for the degree of MDS in the Faculty of Dentistry, The University of Hong Kong by ASMP, and supported by CERG grants from The University of Hong Kong.

1. Hormati A A, Fuller J L, Denehy G E. Effect of contamination and mechanical disturbance on the quality of acid-etched enamel. J Amer Dent Assoc 1980; 100:34-38.

2. Gwinnett AJ. The scientific basis of the sealant procedure. J Prev Dent 1976; 3: 15-28.

3. Xie J, Powe, J M, McGuckin R S. In vitro bond strength of two adhesive to enamel and dentine under normal and contaminated condition. Dent Mater 1993; 9: 295-299.

4. Knight J S, Draughn R, Evans MD. Effects of handpiece lubrication on resin-based composite bond strength to enamel. Amer J Dent 1999; 12: 116-118.

5. Sturdevant C M. The Art \& Science of Operative Dentistry. 3rd Edition. St Louis: Mosby, 1995.

6. Degrange M, Roulet J F. Minimally Invasive Restorations with Bonding. Carol Stream: Quintessence, 1997.

7. Baratieri L N. Advanced Operative Dentistry. São Paolo: Quintessence, 1993.

8. Powers $J M$, Finger $W J$, Xie J. Bonding of composite resin to contaminated human enamel and dentine. J Prosthodont 1995; 4: 28-32.

9. Cantwell $K R$, Tunturi $A R$, Manny $V$ R. Noise from high-speed dental handpieces. JAmer Dent Assoc 1960; 61: 571-575

10. Schubert E D, Glorig A. Noise exposure from dental drills. J Amer Dent Assoc 1963; 66: 751-757.

11. Park P R. Effects of sound on dentists. Dent Clin North Amer 1978; 22: 415-429. 